\title{
Sensitivity and specificity of the Bamberg Dementia Screening Test's (BDST) full and short versions: brief screening instruments for geriatric patients that are suitable for infectious environments
}

\author{
Wolfgang Trapp ${ }^{1,2^{*}} \mathbb{D}$, Susanne Röder ${ }^{1}$, Andreas Heid ${ }^{1}$, Pia Billman ${ }^{1}$, Susanne Daiber ${ }^{3}$ and Göran Hajak
}

\begin{abstract}
Background: Currently, many patients suffering from dementia do not have a diagnosis when admitted to geriatric hospitals. This is the case despite an increased risk of complications affecting the length of stay and outcome. Unfortunately, many dementia screening tests cannot be used on geriatric inpatients, who are often bedridden. Therefore, we aimed at evaluating the diagnostic accuracy of a small battery of bedside tasks that require minimal vision and fine motor skills in patients with suspected dementia.

Methods: In this prospective study, the Bamberg Dementia Screening Test (BDST) was administered to a consecutive series of 1295 patients referred for neuropsychological testing. The diagnosis of dementia was confirmed in 1159 and excluded in 136 patients.

Sensitivity and specificity for the first subtest (ultra-short form), the first two subtests (short form), and the total score of the BDST were obtained via receiver operating characteristic curves and compared with the sensitivity and specificity values of the Mini-Mental Status Examination (MMSE).

Results: The overall diagnostic quality of the BDST was superior to the MMSE for mild Alzheimer's dementia (sensitivity and specificity $=.94(95 \% \mathrm{Cl} .92$ to .96$)$ and .82 (95\% Cl .75 to .88) vs. .79 (95\% Cl .76 to .83) and .88 (95\% $\mathrm{Cl} .82$ to .93$)$ ) as well as for other subtypes of mild dementia (sensitivity and specificity $=.91$ ( $95 \% \mathrm{Cl} .88$ to .94$)$ and $.82(95 \% \mathrm{Cl} .75$ to .88$)$ vs. $.72(95 \% \mathrm{Cl} .67$ to .76$)$ and .88 (95\% Cl .82 to .93$)$ ). Even the short form of the BDST was comparable to the MMSE regarding sensitivity and specificity. For moderate dementia, it was possible to identify dementia cases with sufficient and excellent diagnostic quality by using the ultra-short and the short form.

* Correspondence: wolfgang.trapp@sozialstiftung-bamberg.de

'Department of Psychiatry, Sozialstiftung Bamberg, St-.Getreu-Straße 18,

96049 Bamberg, Germany

2Department of Physiological Psychology, Otto-Friedrich University Bamberg,

Markusplatz 3, 96045 Bamberg, Germany

Full list of author information is available at the end of the article

C C The Author(s). 2021 Open Access This article is licensed under a Creative Commons Attribution 4.0 International License, which permits use, sharing, adaptation, distribution and reproduction in any medium or format, as long as you give appropriate credit to the original author(s) and the source, provide a link to the Creative Commons licence, and indicate if changes were made. The images or other third party material in this article are included in the article's Creative Commons licence, unless indicated otherwise in a credit line to the material. If material is not included in the article's Creative Commons licence and your intended use is not permitted by statutory regulation or exceeds the permitted use, you will need to obtain permission directly from the copyright holder. To view a copy of this licence, visit http://creativecommons.org/licenses/by/4.0/. The Creative Commons Public Domain Dedication waiver (http://creativecommons.org/publicdomain/zero/1.0/) applies to the data made available in this article, unless otherwise stated in a credit line to the data. 
(Continued from previous page)

Conclusions: The BDST is able to detect dementia in geriatric hospital settings. If the adaptive algorithm is used, administration time can be reduced to less than 2 min in most cases. Because no test materials have to be exchanged, this test is particularly suitable for infectious environments where contact between the examiner and the person being tested should be minimized.

Keywords: Memory, Dementia, Alzheimer's disease, Diagnostic, Screening test, Sensitivity, Specificity, Geriatrics

\section{Background}

\section{Dementia as a challenge in general hospitals}

Dementia, defined by the World Health Organization's International Classification of Diseases (ICD 10) as a syndrome characterized by a disturbance of multiple higher cortical functions and associated with deterioration in emotional control, social behavior, or motivation, is a major health problem in industrialized countries [1]. At the moment, about 50 million people worldwide [2] are affected. This number is predicted to rise to more than 130 million people worldwide by 2050 [3].

The majority of subjects suffering from symptoms of dementia do not have a dementia diagnosis when admitted to a hospital $[4,5]$ and a substantial part of these undiagnosed patients remain undiscovered during their stay [6].

Early diagnosis is important and highly recommended by the Alzheimer Cooperative Valuation in Europe [7]. However, less than half of the people in the general population suffering from dementia receive a formal diagnosis [7-9], although this would be important for several reasons: First, interventions to slow down the progression of cognitive deficits could be initiated. Second, care plans could be implemented while patients still have legal capacity and third, institutionalization might be postponed [10]. Furthermore, all these interventions have proven to enhance quality of life and to delay admission to institutional care $[11,12]$.

Whereas routine screening of older adults for dementia in the community may not make sense [13], it might be advisable for older people in general hospitals, who form a substantial part of the population treated there [14]. Estimates of the prevalence of dementia in elderly patients of general hospitals range from 15 to $42 \%$ [1416], which is a much higher proportion compared to the prevalence rates in the general population. Several lines of evidence suggest identifying these patients as soon as possible after admission, as they are more difficult to care for [15] and have an increased risk of complications like falls, poor nutrition, or hydration [17], which affect their length of stay [16] and their outcome [18].

\section{Why still another dementia screening test?}

The findings presented above provide strong arguments towards performing cognitive screenings for geriatric patients in general hospitals. Several validated screening measures have proven sufficient accuracy ruling in patients with suspected dementia and ruling out patients without any cognitive impairment and are recommended for dementia screening in current guidelines [19-21]. However, these tests place high demands on the elderly being tested. This includes the ability to perform fine motor skills like drawing, writing, or the demonstration of complex gestures and vision, reading of texts, connecting figures by lines, and complex test instructions and materials. All of them significantly hamper their application in geriatric, often bedridden inpatients in general hospitals.

Hence, our goal was to develop a small battery of true bedside tasks that can be administered without any special materials and assure a sensitive and valid assessment of dementia in hospital settings. The Bamberg Dementia Screening Test (BDST) was used as a basis because its tasks do not require the participant to write, read or draw on paper, and require minimal demands regarding vision and fine motor skills. Pilot results regarding the validity and diagnostic accuracy for the BDST battery, obtained from a small sample, had been very encouraging [22]. Our objective in this study was to crossvalidate these results and to evaluate the sensitivity and specificity of the full and two shortened versions in a larger sample. Based on these results, our goal was to provide an adaptive mode of administration with shortened administration time (offering an algorithm for "short" and "ultra-short" versions) for patients with mild but also pronounced cognitive impairments.

Our primary goals in this study were

a) To examine whether the BDST's true bedside tasks with minimal demands on vision and fine motor skills and brief application time of about $7 \mathrm{~min}$ can detect possible cases of dementia in a hospital setting,

b) To examine whether shorter versions of the test could be used to reduce the testing effort for patients and test providers, and

c) To develop an application algorithm for BDST versions.

\section{Methods}

\section{Participants}

In this prospective study, a consecutive series of patients who were referred for neuropsychological testing on a 
routine basis, because of a suspected cognitive decline or due to their wish, were recruited from the departments of geriatric internal medicine and geriatric psychiatry of a general hospital in Bamberg, Germany, between January 2016 and February 2020. All of them underwent routine laboratory screening including thyroid function parameters, lues serology, B12 and folic acid levels, a cranial computer tomography (CT) or magnetic resonance imaging (MRI) scan, EEG, ECG, and a thorough psychiatric, neurological, and physical examination to secure a dementia diagnosis.

The neuropsychological tests and other diagnostic procedures were performed during the same inpatient stay, i.e., within 1 week before or after the index test (BDST, see below). All patients were seen by a senior psychiatrist. The decision as to whether the examined patient had dementia was made at a multidisciplinary meeting using ICD 10 criteria for the diagnosis of dementia as well as additional established criteria [23-29] for the diagnosis of mild cognitive impairment (MCI) and dementia subtypes. Participants diagnosed with mild cognitive impairment and patients exhibiting significant depressive symptoms, which could influence the test results, were excluded.

\section{Neuropsychological test battery and symptom measures}

The German version of the Consortium to Establish a Rationale in Alzheimer's Diagnostic neuropsychological battery (CERAD-Plus, [30]) and the Bamberg Dementia Screening Test (BDST [22];) were administered to all participants.

In its current version, the CERAD-Plus battery includes the Mini-Mental State Examination (MMSE [31]; and eleven other tasks covering phonematic fluency, semantic fluency, naming (Boston Naming Test), word list learning, delayed free recall and recognition of a word list, figure drawing (copying geometric shapes), delayed figure recall, and the Trail Making Tests, forms A and B.

Statistical analyses included raw scores for all the CERAD-Plus and BDST subtests as well as total scores for the MMSE and the BDST.

The BDST can be administered in about $7 \mathrm{~min}$ and consists of six brief subtests (see Table 1 for cognitive domains, scoring and sample items; domain and total scores are obtained by simply adding the scores for the corresponding items). No test materials are needed and the participants do not have to read, write, draw on paper, or perform complex gestures. Test forms including instructions in English and German are included in the supplemental material (Additional file 1: BDST test form in English (PDF), Additional file 2: BDST test form in German (PDF)).

To evaluate under which circumstances a shortened version of the BDST would be sufficient, the BDST total sum score, the score for the first subtest ("ultra-short form," denoted as BDST $\mathrm{us}_{\text {is }}$ in the following text), and the sum score for the first and second subtest ("short form," denoted as $\mathrm{BDST}_{\mathrm{s}}$ in the following text) were used for further analyses. The two tests were given within the same test session.

The tests were performed by seven neuropsychologists (S.R., A.H., P.B., W. T and the three colleagues we have thanked in the "Acknowledgments" section) with several years of experience in performing relevant diagnostic tests in people with dementia. All of them were trained to perform the BDST by the first author.

The CERAD-Plus but not the BDST results were available to the senior psychiatrists or senior internists and their multidisciplinary team. Additionally, the MMSE scores-following the German Guideline for dementia [19]-were considered to distinguish between mild and moderate forms of dementia. Thus, the BDST results were not available to the persons who constructed the reference standard.

Furthermore, all patients completed the German short version of the Geriatric Depression Scale (GDS) [32], a brief screening instrument for depressive symptoms in the elderly. Participants with GDS scores higher than 5, indicating possible depression, were excluded.

CERAD-Plus, BDST, and GDS were administered by psychologists of the geriatric or psychiatric ward.

\section{Statistical analyses}

\section{Comparability of the three diagnostic groups}

Univariate analyses of variance with Scheffé a posteriori analyses were performed to compare age, GDS scores, and years of education in the four diagnostic groups $\left(\mathrm{CNT}, \mathrm{DEM}_{\text {mi alz }}, \mathrm{DEM}_{\text {mi } \_ \text {other, }}\right.$, and $\left.\mathrm{DEM}_{\text {mo }}\right)$ and a chisquare test was used to test for comparison of the male to female ratio across these groups.

\section{Validity and diagnostic quality of the BDST}

To gather information about the BDST's concurrent validity, Pearson correlation coefficients were computed between BDST and CERAD-Plus subtasks and total scores. Following the procedure suggested by Schmidt et al. [33], a CERAD "composite" value was obtained by extracting one principal component from the highly intercorrelated CERAD-Plus subtests to obtain one summative CERAD score that can be correlated with the BDST and MMSE total scores.

Univariate analyses of variance with Scheffé a posteriori analyses were performed to compare the diagnostic groups' (CNT, DEM $\mathrm{mi}_{\text {_alz }}, \mathrm{DEM}_{\mathrm{mi} \_ \text {nonalz }}$, and $\mathrm{DEM}_{\mathrm{mo}}$ ) BDST scores. 
Table 1 Cognitive domains, scoring and sample items of the BDST

\begin{tabular}{ll}
\hline Cognitive domain & Task and sample item \\
\hline $\begin{array}{l}\text { Semantic memory } \\
\text { (5 items, maximum score: } 10\end{array}$ & $\begin{array}{l}\text { Items } \mathbf{1} \text { to } \mathbf{4} \\
\text { points) }\end{array}$ \\
$\begin{array}{l}\text { Verbal descriptions of animals are given (e.g., "What is the name of the animal with the very long neck"). If the } \\
\text { correct name is given ("giraffe"), } 2 \text { points are awarded. Otherwise, an additional hint is given (e.g., "The animal } \\
\text { lives in } \mathbf{5} \text { serves and has a yellow -brownish pattern"). If the answer is now correct, } 1 \text { point is awarded. } \\
\text { "Are people more afraid of a lion: or a rabbit?" } \\
\text { If the answer is "lion," 1 point is scored and an additional question is asked: "Why should you be more afraid } \\
\text { of a lion?" For a correct answer ("dangerous," "carnivore," etc., not: "bigger"), the participant receives another point. }\end{array}$
\end{tabular}

Verbal memory

(4 items, maximum score: 8 points)

Visual construction

(4 items, maximum score: 8 points)

\section{Free recall}

remembered correctly, 2 points are given.

\section{Recognition}

For each animal that could not be remembered, the participant is allowed to choose between three options ("Did I ask about a leopard, a giraffe or a parrot?"). If the correct animal is selected, 1 point is awarded.

The participant is asked to draw shapes with the index finger. "Please watch carefully [administrator draws a symbol with her/his index finger] and then try to draw the following shapes in the air." Example:

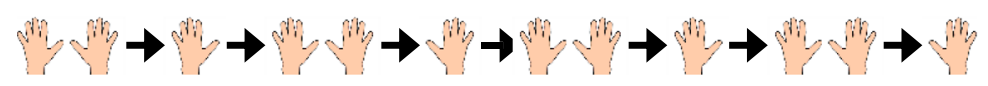

If the shape is drawn correctly by the participant (shape can be clearly recognized, regardless if a mirror image is drawn or not) 2 points are awarded. If not, the shape is repeated by the administrator ("I'll draw the shape again .... Please try again now"). If the shape is now drawn correctly, 1 point is awarded.

Verbal fluency

(1 item, maximum score: 8 points)

Visual memory

(4 items, maximum score: 8 points)

Cognitive flexibility

(4 items, maximum score: 8 points)

Naming of larger cities ( $\geq 50,000$ inhabitants) anywhere in the world in 60 s. 1 point is awarded for each 3 cities (8 points for 24 or more cities).

\section{Free recall}

"What figures did we draw in the air before we talked about big cities?" For each shape that was remembered correctly, 2 points are given.

\section{Recognition}

For the remaining shapes that could not be remembered, hints are given ("one shape looked like a letter"). If the correct shape is drawn, one point is awarded.

The participant is asked to reproduce tapping patterns given by the administrator ("Please watch carefully and then try tapping the same pattern').

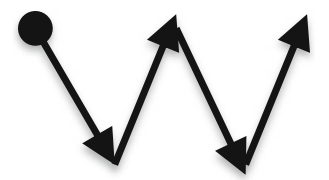

If the pattern is reproduced correctly, 2 points are awarded. If not, the pattern is given again by the administrator ("I'll tap the pattern again .... Please try again now"). If the pattern is now reproduced correctly, 1 point is awarded.

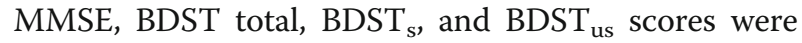
used to plot receiver operating characteristic (ROC) curves of sensitivity against 1-specificity. This was done

- Using MMSE, BDST total, and BDST $\mathrm{B}_{\mathrm{s}}$ scores for mild dementia vs. control subjects, for $\mathrm{DEM}_{\text {mi_alz }}$ vs.

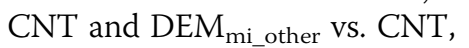

- Using BDST total, BDST ${ }_{\mathrm{s}}$, and BDST $\mathrm{Bs}_{\mathrm{us}}$ scores for moderate dementia vs. control subjects, and

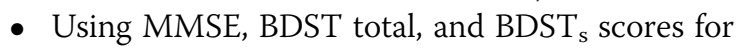
mild or moderate dementia vs. control subjects

The different ROC curves were compared using the pROC - package [34] of $\mathrm{R}$ [35], which utilizes the formula provided by [36] for paired ROC curves. The
pROC - package also computes tests for unpaired ROC curves where the $p$ value is computed with an unpaired $t$-test with unequal sample size and unequal variance.

Optimum cutoff scores were determined using the Youden index. Sensitivity and specificity were computed for all screening measures based on the cutoff scores found.

Sensitivity ("How many persons that are suffering from dementia are detected by a screening test?") and specificity ("How many persons showing no cognitive deficits are correctly categorized as unimpaired by the screening?") refer to a situation where the "true diagnosis" (for example "mild dementia" vs. "cognitively unimpaired") is known.

Unfortunately, this is not the case in practice, where the "true diagnosis" has to be inferred from the result of a screening test. The positive predictive value specifies to what extent a screening test indicating a diagnosis (in 
our case for example: "mild dementia") is right. Even more importantly, the negative predictive value answers the question to what extent an inconspicuous test result, which prevents further diagnostic or protective action (for example to protect dementia patients in a geriatric ward), is correct. Although positive and negative predictive values depend on sensitivity and specificity, they also vary with the prevalence of the diagnostic condition (i.e., the percentage of people suffering from dementia) in a specific setting. Therefore, curves of negative predictive values against the prevalence of dementia are plotted based on the sensitivities and specificities found in the ROC analyses described above.

\section{Effects of age, gender, and years of education on BDST performance}

BDST scores were correlated with age, gender, and years of education using Pearson correlation coefficients.

To estimate to what extent the BDST scores are influenced by age, gender, and years of education independently from cognitive achievement, three stepwise linear regressions were performed using the BDST total, $\mathrm{BDST}_{\mathrm{s}}$, or $\mathrm{BDST}_{\mathrm{us}}$ scores as dependent variable and all CERAD-Plus scores as well as gender, age, and years of education as predictors in order to examine whether age, gender, and years of education or cognitive achievement primarily influence test performance.

The significance level was set to $\alpha<0.05$, two-tailed, for all analyses.

\section{Results}

\section{Sample characteristics}

In total, 1905 potentially eligible patients were referred for neuropsychological testing. Seventy two of them were discharged before testing or a thorough diagnosis could be performed and 23 did not agree to participate. For 20 patients, other causes of cognitive decline were identified (three patients were found to have had a stroke and 17 participants suffered from WernickeKorsakoff syndrome caused by alcohol abuse). In total, 292 participants were excluded because of significant depressive symptoms and 186 patients because of a diagnosis of MCI. Seventeen participants were unable to perform the neuropsychological test battery because of severe hearing or visual impairments.

Of the remaining 1295 participants, 883 met diagnostic criteria for mild dementia. A total of 519 of these were suffering from Alzheimer's disease $\left(\mathrm{DEM}_{\mathrm{mi} \_a l z}\right)$ and the remaining 364 received a dementia diagnosis other

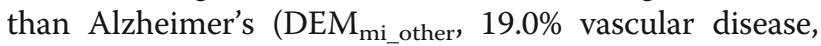
19.6\% frontotemporal disease, 1.9\% Parkinson's disease dementia, and $0.7 \%$ Levy Body dementia). In total, 276 participants met criteria for moderate dementia $\left(\mathrm{DEM}_{\mathrm{mo}}\right)$. Then, 136 showed no signs of cognitive impairment and were thus included as clinical control sample (CNT).

No significant differences were found between the four groups concerning age $\left(\mathrm{F}_{(3,1291)}=1.029, p=.379\right)$, GDS scores $\left(\mathrm{F}_{(3,1291)}=.606, p=.611\right)$, years of education $\left(\mathrm{F}_{(3,1291)}=1.100, p=.348\right)$, and gender $\left(\chi^{2}{ }_{(3)}=4.089, p=\right.$ .252), see also Table 2 for more detailed information about the sample.

\section{Validity and diagnostic accuracy}

Table 3 shows correlation coefficients between all BDST and selected CERAD-Plus subtests of corresponding content. Subtests covering similar contents yielded meaningful correlations between each other. Remarkably, even conceptually similar subtests differing remarkably in their mode of presentation (recognition of tapping patterns vs. connecting of letters and figures, recall of simple shapes drawn in the air vs. recall of geometric shapes drawn on paper) were substantially correlated.

High correlations were found for the BDST total score and the MMSE and CERAD-Plus total scores $(r=.71$ and $r=.77$ respectively, $p<.0005$ each). Even the shortened versions of the BDST $\left(\mathrm{BDST}_{\mathrm{s}}, r=.60\right.$ and $r=.56$ and $\mathrm{BDST}_{\mathrm{us}}, r=.49$ and $r=.42, p<.0005$ for all coefficients) are still moderately related to the MMSE and CERAD-Plus total scores.

All BDST subtest scores, the BDST total score and the two shortened versions of the BDST differentiated between the four groups $\left(\mathrm{F}_{(3,1291)}\right.$ between 274.742 and 86.810, $p<.0005$ each, see also Fig. 1$)$.

Scheffé a posteriori comparisons indicate that all BDST scores were different for control subjects, patients with mild and patients with moderate dementia $\left(p<.0005\right.$ for each comparison). Additionally, $\mathrm{DEM}_{\mathrm{mi} \text { alz }}$ patients scored lower than DEM $M_{\text {mi_other }}$ patients in the verbal and visual memory subtests $(p<.0005$ each), whereas DEM $_{\text {mi_other }}$ patients scored lower than DEMmi_alz patients in the cognitive flexibility task of the $\operatorname{BDST}(p=.002)$.

Table 4 shows the results of the ROC analyses regarding the diagnostic accuracy of the MMSE and BDST scores for the diagnosis of mild and moderate dementia.

The characteristics show that both MMSE and BDST are slightly better at detecting patients suffering from mild Alzheimer's disease than patients suffering from other mild forms of dementia. The areas under the curve (AUC) indicate that the overall diagnostic quality of the full version of the BDST is superior to the MMSE. The full version of the BDST outperforms the MMSE for all participants with mild dementia $(z=4.784, p<.0005)$, as well as the two subsamples of participants with Alzheimer's disease $(z=3.927$, $p<.0005)$ and other forms of dementia $(z=4.706$, $p<.0005)$. Similar results are obtained when all patients 
Table 2 Sample characteristics. SD standard deviation, CNT clinical control sample, DEM mi mild dementia, DEM mi_alz mild dementia, Alzheimer's disease, DEM mi_other mild dementia, other forms, DEMmo moderate dementia, TMT A Trail Making Test Form A, TMT B Trail Making Test Form B

\begin{tabular}{|c|c|c|c|c|c|}
\hline & $\begin{array}{l}\text { CNT } \\
(n=136)\end{array}$ & $\begin{array}{l}\mathrm{DEM}_{\mathrm{mi}} \\
(n=883)\end{array}$ & $\begin{array}{l}\text { DEM }_{\text {mi_alz }} \\
(n=519)\end{array}$ & $\begin{array}{l}\text { DEM } \\
(n=364) \\
(n=\text { other }\end{array}$ & $\begin{array}{l}\mathrm{DEM}_{\mathrm{mo}} \\
(n=276)\end{array}$ \\
\hline \multirow[t]{3}{*}{ Gender } & female/male & female/male & female/male & female/male & female/male \\
\hline & $80 / 56$ & $544 / 339$ & $332 / 187$ & $212 / 152$ & $161 / 115$ \\
\hline & mean (SD) & mean (SD) & mean (SD) & mean (SD) & mean (SD) \\
\hline Age & $75.64(7.82)$ & $76.34(8.45)$ & $76.67(8.50)$ & $75.87(8.41)$ & $76.33(6.43)$ \\
\hline Years of education & $12.13(2.02)$ & $12.04(1.94)$ & $12.01(1.93)$ & $12.09(1.97)$ & $11.84(1.75)$ \\
\hline GDS & $3.75(3.29)$ & $3.74(3.29)$ & $3.66(3.45)$ & $3.83(3.07)$ & $3.45(3.12)$ \\
\hline \multicolumn{6}{|l|}{ BDST } \\
\hline Total score & $41.29(4.06)$ & $29.61(5.87)$ & $29.21(5.66)$ & $30.16(6.11)$ & $19.66(5.40)$ \\
\hline Short form & $16.81(1.13)$ & $14.00(2.75)$ & $13.62(2.75)$ & $14.54(2.67)$ & $9.96(3.61)$ \\
\hline Semantic memory (=ultra-short form) & $9.76(.62)$ & $8.81(1.62)$ & $8.78(1.61)$ & $8.85(1.64)$ & $6.72(2.46)$ \\
\hline Verbal memory & $7.04(.86)$ & $5.19(1.75)$ & $4.84(1.81)$ & $5.70(1.54)$ & $3.24(1.99)$ \\
\hline Visual construction & $7.67(.59)$ & $6.41(1.69)$ & $6.52(1.58)$ & $6.25(1.82)$ & $4.76(2.15)$ \\
\hline Verbal Fluency & $4.33(3.16)$ & $2.05(1.86)$ & $2.00(1.88)$ & $2.12(1.84)$ & $1.07(1.25)$ \\
\hline Visual memory & $6.99(1.16)$ & $3.43(2.08)$ & $3.15(1.96)$ & $3.84(2.19)$ & $1.38(1.45)$ \\
\hline Cognitive flexibility & $5.42(1.56)$ & $3.63(1.38)$ & $3.78(1.45)$ & $3.42(1.25)$ & $2.75(1.14)$ \\
\hline \multicolumn{6}{|l|}{ MMSE } \\
\hline Total score & $28.14(1.79)$ & $24.09(3.02)$ & $23.78(2.88)$ & $24.53(3.16)$ & $15.80(3.15)$ \\
\hline \multicolumn{6}{|l|}{ CERAD-Plus } \\
\hline Semantic fluency & $20.38(5.41)$ & $12.06(4.25)$ & $12.03(4.40)$ & $12.10(4.04)$ & $7.53(3.57)$ \\
\hline Boston naming test & $14.18(1.08)$ & $12.06(2.21)$ & $12.10(2.18)$ & $12.00(2.25)$ & $10.14(2.60)$ \\
\hline $\begin{array}{l}\text { Word list } \\
\text { learning }\end{array}$ & $18.82(2.97)$ & $11.71(3.88)$ & $10.76(3.63)$ & $13.05(3.83)$ & $7.94(3.93)$ \\
\hline Word list delayed free recall & $6.21(1.61)$ & $2.55(2.00)$ & $1.65(1.55)$ & $3.83(1.86)$ & $1.11(1.55)$ \\
\hline Percent word list recognition & $96.36(8.20)$ & $83.46(13.50)$ & 78.67 (13.79) & $90.24(9.64)$ & $71.18(14.09)$ \\
\hline Figure drawing & $10.61(.79)$ & $8.83(1.879$ & $8.94(1.82)$ & $8.67(1.93)$ & $7.05(2.48)$ \\
\hline Delayed recall figures & $8.43(2.43)$ & $3.09(2.75)$ & $2.42(2.57)$ & $4.04(2.73)$ & $1.01(1.96)$ \\
\hline TMT A & $51.83(18.40)$ & $102.95(45.1)$ & $98.63(45.29)$ & $108.78(44.03)$ & $156.65(37.33)$ \\
\hline TMT B & $135.17(52.97)$ & $268.96(57.30)$ & $262.37(63.96)$ & $277.79(45.52)$ & $299.71(2.74)$ \\
\hline Phonematic fluency & $11.80(4.15)$ & $6.90(3.74)$ & 7.19 (3.74) & $6.49(3.70)$ & $5.11(3.45)$ \\
\hline
\end{tabular}

with mild or moderate dementia are taken into account (right column of Table 4, $z=4.619, p<.0005$ ). The AUCs for the short form of the BDST and the MMSE do not differ significantly when patients with mild dementia are considered $(z=1.665, p=.096$ for all, $z=1.015, p=.310$ for Alzheimer's disease and $z=1.949, p=.051$ for other forms), or when all patients with mild or moderate dementia are taken into account $(z=1.949, p=.051)$.

Whereas the overall diagnostic quality of the MMSE $(z=2.101, p=.036)$ and the $\operatorname{BDST}_{\mathrm{s}}(z=3.110, p=.002)$ is higher for patients with mild Alzheimer's disease than for patients with other mild forms of dementia, no such difference for the long form of the BDST could be found $(z=1.395, p=.163)$.
For moderate dementia, even the first subtest of the BDST $\left(B_{\text {DST }}\right.$ score) seems to be sufficient to detect dementia with reasonable sensitivity and specificity, while the first two subtests BDST $_{\mathrm{s}}$ score) do so with excellent diagnostic quality.

In Fig. 2, the negative predictive values (no further action indicated according to the test result) are plotted against the estimated prevalence of dementia. It can be seen that the BDST shows excellent negative predictive values superior to the MMSE, even for populations with up to $70 \%$ of dementia cases. Again, both measures' values are marginally higher for Alzheimer's disease than for other types of dementia. Even the shortened version of the BDST (BDST $)$ shows slightly better negative predictive values than the 
Table 3 Correlations between BDST and CERAD-Plus scores corresponding in content ( $p<.0005$ for all coefficients, TMT B: Trail Making Test B)

\begin{tabular}{|c|c|c|c|}
\hline \multirow{2}{*}{$\begin{array}{l}\text { BDST subtest } \\
\text { Semantic memory }\end{array}$} & \multicolumn{3}{|c|}{ corresponding CERAD-Plus subtests } \\
\hline & \multicolumn{2}{|c|}{ Boston naming test } & Semantic fluency \\
\hline & \multicolumn{2}{|l|}{.54} & .44 \\
\hline \multirow[t]{3}{*}{ Verbal memory } & \multicolumn{3}{|l|}{ Word list } \\
\hline & Learning & Delayed free recall & Recognition \\
\hline & .47 & .49 & .41 \\
\hline \multirow[t]{2}{*}{ Visual construction } & \multicolumn{3}{|c|}{ Figure drawing } \\
\hline & \multicolumn{3}{|l|}{.42} \\
\hline \multirow[t]{3}{*}{ Verbal fluency } & \multicolumn{2}{|l|}{ Fluency } & TMT В \\
\hline & Semantic & Phonematic & \\
\hline & .68 & .54 & -.56 \\
\hline \multirow[t]{2}{*}{ Visual memory } & \multicolumn{3}{|c|}{ Delayed recall figures } \\
\hline & \multicolumn{3}{|l|}{.57} \\
\hline \multirow[t]{2}{*}{ Cognitive flexibility } & \multicolumn{3}{|l|}{ TMT B } \\
\hline & \multicolumn{3}{|l|}{-.52} \\
\hline
\end{tabular}

MMSE. For cases with moderate dementia, the brief version $\left(\mathrm{BDST}_{\mathrm{s}}\right)$ might be sufficient in many cases. Even when the very brief $\mathrm{BDST}_{\mathrm{us}}$ score is used, only few patients remain unidentified in the majority of scenarios.

Effects of age, gender, and education on BDST test scores Only minor correlations of age, gender, and years of education could be found with the three BDST scores
( $r=-.20$ to .10 , see also Additional file 3: Correlations of the BDST scores with age, gender, and years of education).

When years of education, gender, and age together with all CERAD-Plus subscores including the MMSE are entered as predictors in a stepwise linear regression using the three BDST scores as dependent variable, only the CERAD-Plus scores remain as significant predictors (BDST: MMSE (beta $=.277$ ), Boston Naming Test (beta $=.198)$, delayed recall figures (beta $=.165)$, semantic fluency (beta $=.156)$, TMT B (beta $=-.119)$, word list learning (beta $=.125)$, and figure drawing (beta $=.074$ ) $p<.0005$ each except figure drawing: $p=.002 ; \mathrm{BDST}_{\mathrm{s}}$ : MMSE (beta $=.238$ ), Boston Naming Test (beta $=.294$ ), word list learning (beta $=.120$ ), semantic fluency (beta $=$ .140 ), word list recognition (beta $=.106$ ), figure drawing (beta $=-.090)$, and TMT B (beta $=-.059), p<.0005$ each except figure drawing: $p=.001$ and TMT B: $p=.031$, BDST $_{\text {us: }}$ Boston Naming Test (beta $=.413$ ), MMSE $($ beta $=.159)$, and semantic fluency $($ beta $=.138) p<.0005$ each).

\section{Discussion}

In a large sample of 1295 participants, it could be shown that the BDST shows high sensitivity and sufficient specificity regarding the detection of mild dementia. Thereby, the BDST cutoff score of $\leq 37 / 50$ for mild dementia obtained in a smaller sample of a previous study [22] could be cross-validated.

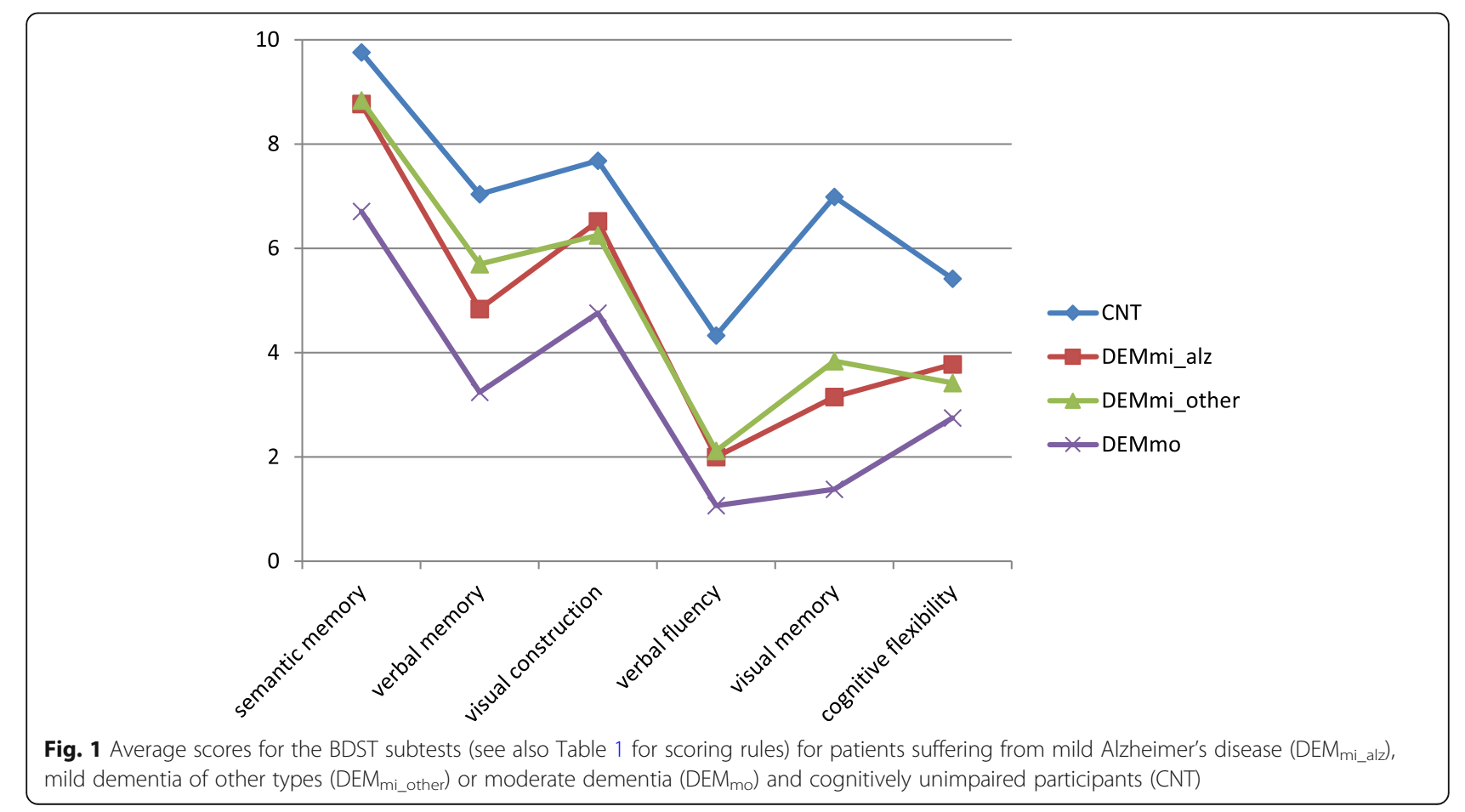


Table 4 Diagnostic accuracy of the BDST and the MMSE (95\% confidence intervals in parentheses). SEN sensitivity, SPE specificity, AUC area under the curve, Dem mo moderate dementia, Dem mi mild dementia, Dem mi_alz mild dementia Alzheimer's disease, Dem mi_other mild dementia, other types than Alzheimer's disease, BDST Bamberg Dementia Screening Test, BDST $T_{s}$ Bamberg Dementia Screening Test, short form (sum score for the first and second subtest), BDST us Bamberg Dementia Screening Test, ultra-short form (only score for the first subtest), MMST Mini-Mental State Examination. (1) Following the German Guideline for dementia, the MMSE scores were considered to distinguish between mild and moderate forms of dementia. Therefore, no measures of diagnostic accuracy can be presented for the MMSE and moderate dementia

\begin{tabular}{|c|c|c|c|c|c|c|}
\hline & & Dem $_{\text {mo }}$ vs. CNT & Dem $_{m i}$ vs. CNT & $\begin{array}{l}\text { Dem }_{\text {mi alz }} \\
\text { vs. CNT }\end{array}$ & $\begin{array}{l}\text { Dem }_{\text {mi_other }} \\
\text { vs. CNT }\end{array}$ & $\begin{array}{l}\text { Dem }_{m i} \text { or } \text { Dem }_{\text {mo }} \\
\text { vs. CNT }\end{array}$ \\
\hline \multirow[t]{6}{*}{ MMSE } & Cut-off & (1) & $\leq 26 / 30$ & $\leq 26 / 30$ & $\leq 26 / 30$ & $\leq 26 / 30$ \\
\hline & SEN & & $.76(.73-.79)$ & $.79(.76-.83)$ & $.72(.67-.76)$ & $.81(.79-.83)$ \\
\hline & SPE & & $.88(.82-.93)$ & $.88(.82-.93)$ & $.88(.82-.93)$ & $.88(.82-.93)$ \\
\hline & NPV & & $.36(.31-.41)$ & $.52(.46-.59)$ & $.54(.47-.60)$ & $.35(.30-.40)$ \\
\hline & PPV & & $.98(.96-.99)$ & $.96(.94-.98)$ & $.94(.91-.97)$ & $.98(.97-.99)$ \\
\hline & $A \cup C$ & & $.88(.86-.91)$ & $.90(.88-.92)$ & $.86(.83-.88)$ & $.91(.89-.93)$ \\
\hline \multirow[t]{6}{*}{ BDST } & Cut-off & $\leq 31 / 50$ & $\leq 37 / 50$ & $\leq 37 / 50$ & $\leq 37 / 50$ & $\leq 37 / 50$ \\
\hline & SEN & 1.000 & $.93(.91-.94)$ & $.94(.92-.96)$ & $.91(.88-.94)$ & $.94(.93-.95)$ \\
\hline & SPE & 1.000 & $.82(.75-.88)$ & $.82(.75-.88)$ & $.82(.75-.88)$ & $.82(.75-.88)$ \\
\hline & NPV & & $.63(.56-.70)$ & $.77(.70-.84)$ & $.77(.70-.84)$ & $.62(.54-.69)$ \\
\hline & PPV & & $.97(.96-.98)$ & $.95(.93-.97)$ & $.93(.90-.96)$ & $.98(.97-.99)$ \\
\hline & $A \cup C$ & 1.000 & $.95(.94-.97)$ & $.96(.95-.97)$ & $.94(.92-.96)$ & $.96(.95-.97)$ \\
\hline \multirow[t]{6}{*}{$\mathrm{BDST}_{\mathrm{s}}$} & Cut-off & $\leq 15 / 18$ & $\leq 16 / 18$ & $\leq 16 / 18$ & $\leq 16 / 18$ & $\leq 16 / 18$ \\
\hline & SEN & $.94(.91-.96)$ & $.84(.81-.86)$ & $.87(.85-.90)$ & $.79(.75-.83)$ & $.86(.84-.88)$ \\
\hline & SPE & $.93(.89-.97)$ & $.70(.62-.77)$ & $.70(.62-.77)$ & $.70(.62-.77)$ & $.70(.62-.77)$ \\
\hline & NPV & $.88(.82-.93)$ & $.40(.34-.46)$ & $.59(.52-.67)$ & $.55(.48-.62)$ & $.26(.22-.30)$ \\
\hline & PPV & $.97(.94-.99)$ & $.95(.93-.96)$ & $.92(.89-.94)$ & $.87(.84-.91)$ & $.99(.98-.99)$ \\
\hline & $A \cup C$ & $.97(.95-.98)$ & $.86(.83-.88)$ & $.89(.86-.91)$ & $.81(.78-.85)$ & $.88(.86-.90)$ \\
\hline \multirow[t]{6}{*}{$\mathrm{BDST}_{\text {us }}$} & Cut-off & $\leq 9 / 10$ & - & - & - & $\leq 9 / 10$ \\
\hline & SEN & $.85(.81-.89)$ & & & & $.58(.55-.61)$ \\
\hline & SPE & $.86(.81-.92)$ & & & & $.85(.79-.91)$ \\
\hline & NPV & $.74(.67-.81)$ & & & & $.20(.16-.23)$ \\
\hline & PPV & $.93(.89-.96)$ & & & & $.97(.96-.98)$ \\
\hline & $A \cup C$ & $.90(.87-.93)$ & & & & $.73(.70-.77)$ \\
\hline
\end{tabular}

The full version of the BDST proved superior to the MMSE in detecting dementia. This can be ascribed mainly to higher sensitivity values. For instance, the sensitivity of the MMSE regarding mild forms of dementia is .76, indicating that roughly a quarter of patients might remain undetected, while the corresponding sensitivity value for the BDST of .93 is significantly higher.

Even a shortened BDST version consisting of only the first two subtests was shown to be comparable concerning diagnostic quality while surpassing the MMSE with respect to brevity (16 vs. 30 items), the necessity of test materials (no additional test materials needed vs. pencil, watch and two extra sheets of paper needed) and testing time (less than two minutes vs. seven to eight minutes). Notably, the first subtest, requiring less than $1 \mathrm{~min}$ of administration time, already proved to detect possible moderate dementia with sufficient sensitivity and specificity.

Based on the sensitivity and specificity values found in this study, high negative predictive values would be expected even if the proportion of dementia cases were up to $40 \%$ in the population screened with the BDST.

Table 4 suggests that the $\mathrm{BDST}_{\mathrm{s}}$ has higher sensitivity, but lower specificity than the MMSE, meaning it leads to more false-positive cases. While the PPVs in Table 4 are excellent (which may be a result of its high sensitivity but surely is also due to the fact that there are many more dementia cases than CNT cases in our sample), the NPVs, like for the MMSE, are not satisfactory. Therefore, the $\mathrm{BDST}_{\mathrm{s}}$ should be used as a first-stage screening tool. In case the $\mathrm{BDST}_{\mathrm{s}}$ is positive, patients can be referred to a specialist for a more thorough 

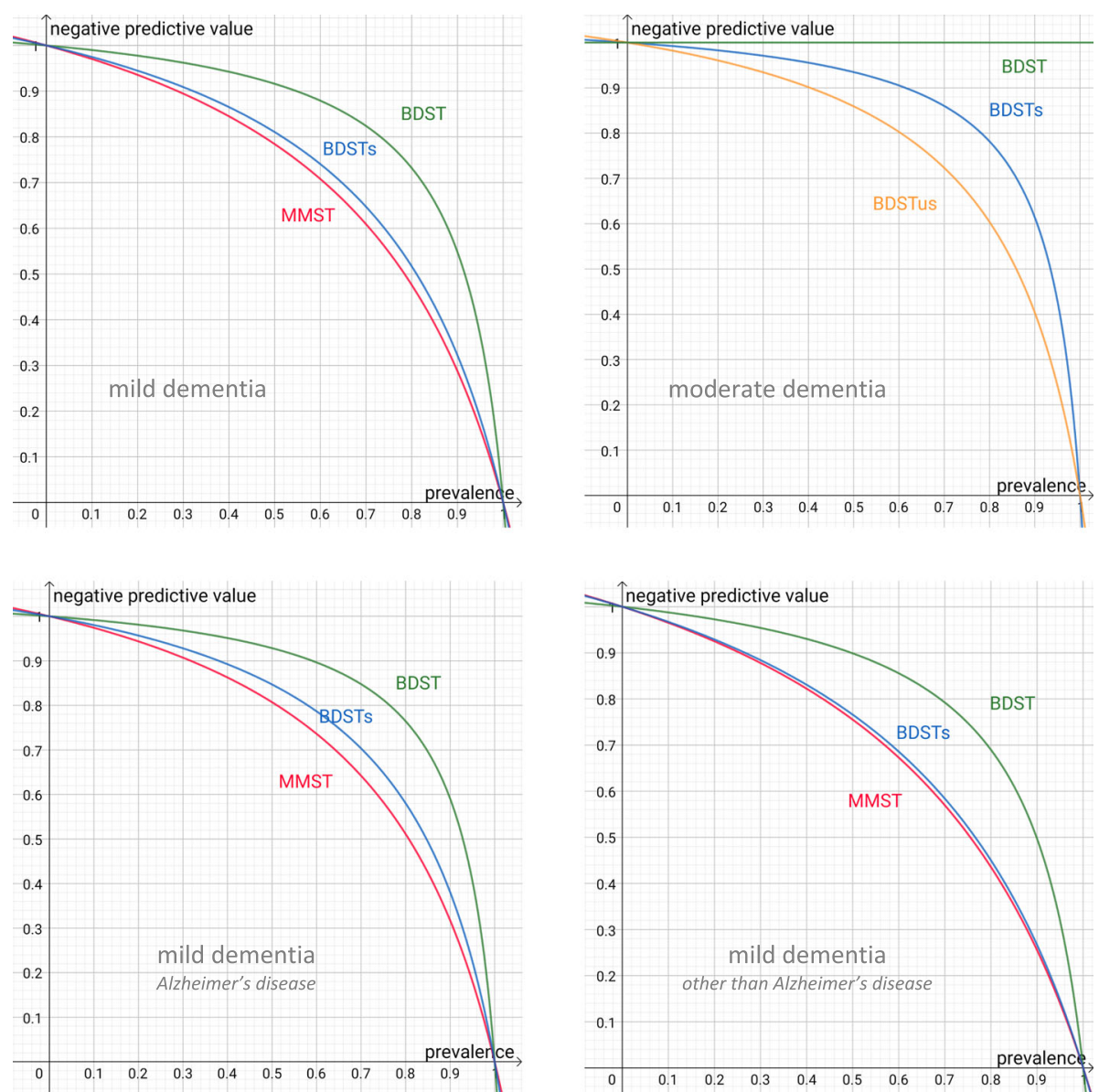

Fig. 2 Calculated negative predictive values depending on the prevalence rate for dementia based on the sensitivities and specificities for the MMSE and different forms of the BDST shown in Table 4. BDST: Bamberg Dementia Screening Test, BDST : Bamberg Dementia Screening Test, short form (sum score for the first and second subtest), BDST us: Bamberg Dementia Screening Test, ultra-short form (only score for the first subtest), MMST: Mini-Mental State Examination. Negative predictive values (no further action indicated according to the test result) computed based on the for prevalence estimates

diagnosis. On the other hand, if the $\mathrm{BDST}_{\mathrm{s}}$ is negative, the remaining subtests of the BDST should also be administered, at least in settings where many dementia cases are to be expected (see also Fig. 2 on this topic).

It can be argued that by lowering cutoffs, a better balance between SN and SP could be obtained. However, lowering the cutoff to $\leq 36 / 50$ decreases sensitivity from .93 to .88 and increases specificity from .82 to .85 , which would lead to an overall worse diagnostic accuracy. We also placed more emphasis on a high detection rate (despite risking a higher false-positive rate), so we decided to keep the cutoff at $\leq 37 / 50$.

These results justify an adaptive algorithm for application as illustrated in Fig. 3. Any mistake in the first subtest (naming of animals) indicates moderate dementia so that the testing can be terminated, and the patient should be referred to psychiatrists and neuropsychologists.
Otherwise, if in the second subtest there is more than one error in the recall of the animals named in the first subtests (for example two animals could only be recognized but not freely recalled), either mild or moderate dementia can be suspected and the test session could also be terminated at this point.

Nevertheless, as the diagnostic quality of the BDST is higher than that of the $\mathrm{BDST}_{\mathrm{s}}$, the full BDST should be administered whenever possible. However, if there is too little time to perform the complete test, taking 1 or 2 min for the abbreviated versions has proven to be better than performing no screening at all. However, especially in settings with high prevalence of true positive cases, a positive $\mathrm{BDST}_{\mathrm{s}}$ score is highly likely to be truly positive, but a negative $\mathrm{BDST}_{\mathrm{s}}$ does not mean very much. As NPVs are low, clinicians should be cautious about over-interpreting a negative test of the $\mathrm{BDST}_{\mathrm{s}}$, especially if the score is close to the cutoff point. 


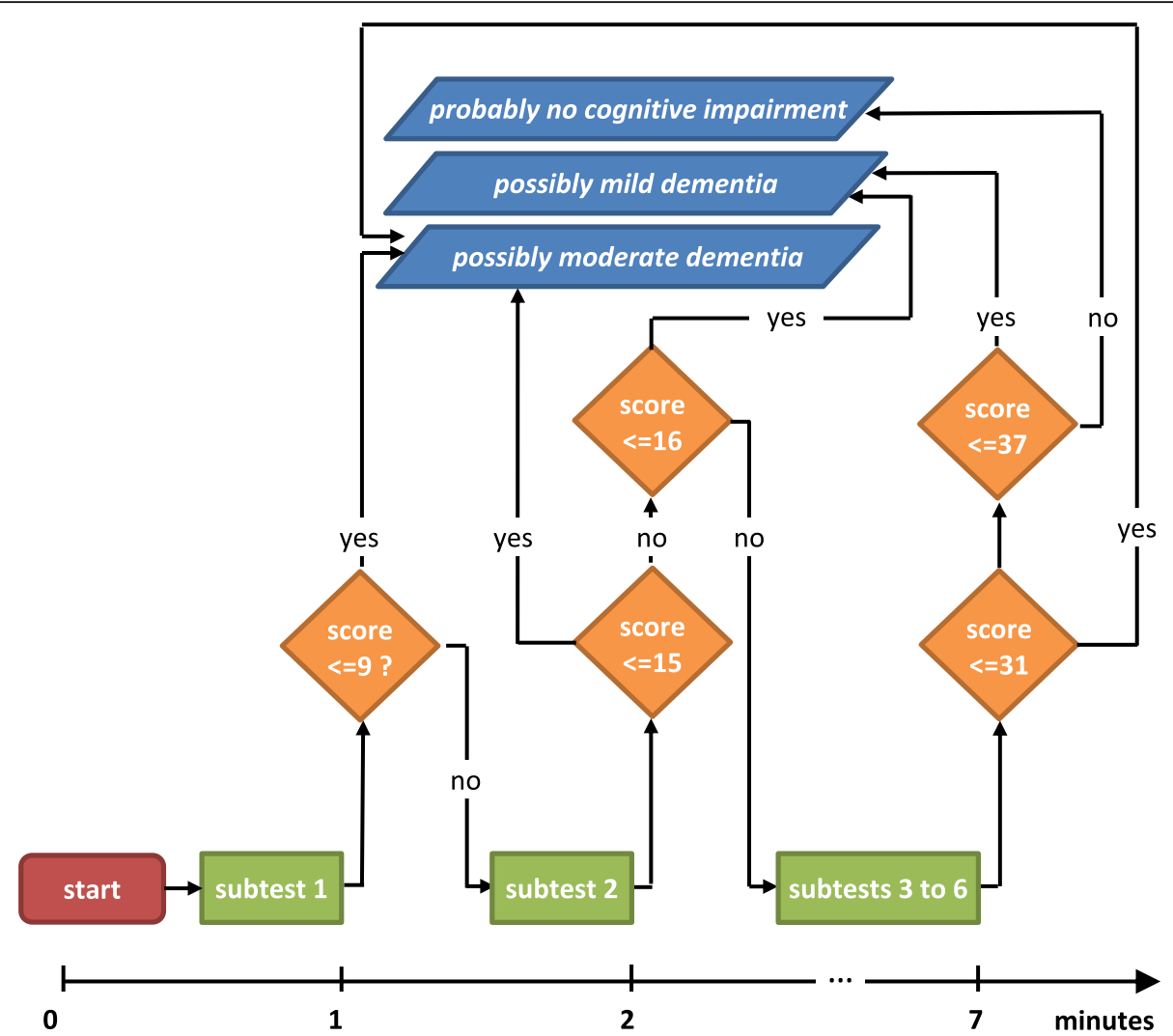

Fig. 3 Algorithm for an adaptive application of the BDST

The BDST was also able to prove sufficient sensitivity and specificity not only for Alzheimer's but also for other types of dementia. Notably, different test profiles matching theoretical expectations for participants suffering from either Alzheimer's or other types of dementia became apparent. As expected, the first subgroup performed worse in the subtests affecting verbal and visual memory while the latter group showed more pronounced deficits in the subtest covering cognitive flexibility. However, as can be seen in Fig. 1, the numerical differences in the scores are very small, and it should be noted that for the other three subtests, no significant differences could be found, which might be caused by the heterogeneity of the non-Alzheimer group. It was not our purpose, though, to develop a screening that can distinguish between Alzheimer's disease and other forms of dementia but to analyze whether the BDST can detect people with dementia, even when they do not suffer from Alzheimer's disease.

The total scores of the BDST, MMSE, and CERADPlus were highly intercorrelated. This was also true for the scores of CERAD-Plus and BDST subtests with similar content. This is remarkable because of the considerably different modes of administration and test behavior that make the BDST administrable even for bedridden patients. These findings provide additional evidence regarding construct validity of the screening measure introduced in this paper.

Another strength of the test is that-although cognitively healthy control patients experienced virtually no difficulties with the completion of the tasks-no ceiling effects for the BDST occurred. The average BDST score was more than two standard deviations below the BDST's maximum score, whereas the average MMSE score obtained in our sample was only about one standard deviation below MMSE's maximum score. Furthermore, no floor effects for subjects suffering from moderate dementia could be detected, as these participants still reached an average score of 20. Thus, the BDST allows for testing a wide range of performance levels of both weakly and strongly impaired individuals, which makes this test particularly suitable for geriatric patients. Furthermore, administration of the BDST does not require investigators to ask considerably basic questions about spatial and temporal orientation, which might be experienced as humiliating and stressful [37].

Also, educational level, gender, or age have shown no substantial effects on test performance, independently of cognitive status, which itself is affected by educational level and age. 
It should not go unmentioned that the advantages of the BDST over the MMSE also apply to many alternative tests for dementia and cognitive impairment like the Montreal Cognitive Assessment (MoCA, [38]), the Addenbrooke's Cognitive Examination III (ACE-III, [39]) or the Test Your Memory (TYM [40]), which have also been shown to outperform the MMSE and to have similar or even better sensitivity and specificity values. The BDST is shorter than most other screenings and can be administered even in cases where conventional screenings cannot be used. For example, if there is minimal time to administer a screening, the TYM, which has excellent diagnostic quality [41], could be a better choice, because, as patients are to fill in the test themselves, administration time is minimized. However, participants must be able to read, write, and draw into relatively small gaps in the test form. For example, a clock face must be drawn into a circle with a diameter of about 3.5 $\mathrm{cm}$ (1.2 in). For participants that are bedridden and too physically ill to meet these requirements, the short and full versions of the BDST could therefore be a viable alternative to the TYM.

It should be noted, however, that poor test performance in cognition tests per se could be due to other reasons than dementia, for example delirium, diabetes, depression, or pain [42]. Hence, prior to using cognitive screening tests, these conditions should be excluded.

Generally, neither the BDST nor any other dementia screening test can replace detailed neuropsychological testing and other diagnostic procedures such as cranial CT or MRI scans, and others. Especially in populations where dementia cases are rare, even screening tests with good sensitivity and specificity have low positive predictive values, i.e., subjects who in reality do not have dementia are to be expected to have falsely positive test results. This is why many authors argue that in clinical settings routine dementia screening is not feasible [43]. To overcome this issue, we recommend that dementia screenings should be combined with a quick and valid screening for delirium, e.g., the 4AT [44], and that the term "dementia" should be avoided until careful diagnostics have been carried out.

It should be pointed out that the data obtained for the BDST in this study and presented in this paper was drawn from a clinical sample of patients referred for neuropsychological testing. Although this might be a valid setting for the BDST in many cases (e.g., in a geriatric ward, a quick assessment might be very helpful), this has led to a high proportion of participants with the target condition (dementia), which possibly affected the PPV and NPV estimates.

Furthermore, by selecting the positivity cutoff after performing the test using ROC analyses, we have increased the risk of too optimistic accuracy estimates.
However, it should be noted that this effect is strongest in smaller samples. As can be seen in Table 4, for the short and the long version of the BDST, the determined cutoff scores for mild dementia stay the same, regardless of whether the whole sample of participants with dementia or the two subsamples of participants with Alzheimer's and other forms of dementia are considered.

Although it should be noted that the cutoff score of $\leq$ $37 / 50$ is a replication of the cutoff score that was determined for a different, albeit smaller sample in a former study [22], our findings have to be cross-validated, desirably in a population-based sample. Furthermore, the development of parallel versions of the BDST would aid in the long-term evaluation of its usefulness in measuring cognitive decline in the course of illness.

When considering the clinical benefits of the BDST test, one has to realize that the identification rate of dementia reporting in hospital records ranges between 26 and $70 \%$ in European and North American countries [45-48], which means that many patients suffering from dementia are overlooked. As no prior preparation or test materials are needed and the BDST is easy to administer and evaluate, this test might help to reduce the barriers of using neuropsychological screening tests in geriatric wards of general hospitals or residents of nursing homes. In the optional BDST smartphone app, which can be obtained from the corresponding author, the user is guided through administration, automated scoring, and interpretation of the results and provided with an automatic suggestion for a medical report text. This could help to avoid potential adverse events like falls or poor hydration, which are more likely to occur in patients suffering from dementia and affect their outcome, for example with regard to institutionalization, mortality, and length of stay [49]. Thus, screening measures like the BDST could help to improve outcome and reduce costs of stays in geriatric wards of general hospitals. The fact that no test utensils (pencils, test forms, written instructions, etc.) have to be exchanged between the examiner and the person being tested makes the BDST especially suitable for dementia screenings in infectious environments or remote telemedical testing via video calls. Thus, in rural regions, where no specialized personal is available, a more timely diagnosis of dementia could be initiated.

\section{Conclusions}

In summary, the data presented here yields evidence that "true bedside" measures like the BDST may qualify as valid screening measures for the diagnosis of dementia. Especially in geriatric settings, such measures might help to avoid unwanted effects on the health of overlooked dementia patients with minimal effort. 


\section{Supplementary Information}

The online version contains supplementary material available at https://doi. org/10.1186/s12916-021-01927-4.

Additional file 1. BDST test form in English.

Additional file 2. BDST test form in German.

Additional file 3. Correlations of the BDST scores with age, gender and years of education.

\section{Abbreviations}

4AT: 4 'A's test for detecting delirium; AUC: Area under the curve; BDST: Bamberg Dementia Screening Test; BDST: Bamberg Dementia Screening Test, short form (sum score for the first and second subtest); BDST $_{\text {us: }}$ Bamberg Dementia Screening Test, ultra-short form (only first subtest); CERAD: Consortium to Establish a Rationale in Alzheimer's Diagnostic; CNT: Clinical control sample; CT: Cranial computer tomography; DEM $M_{\text {mi_alz: }}$ Mild dementia, Alzheimer's disease; DEM mi_other: Mild dementia, other subtypes; DEMmo: Moderate dementia; GDS: Geriatric Depression Scale; ICD: International Classification of Diseases; MMSE: Mini-Mental Status Examination; MRI: Magnetic resonance imaging; ROC: Receiver operating characteristic; SD: Standard deviation

\section{Acknowledgements}

The authors wish to thank the patients who participated in this study as well as Eva Dull, Elisabeth Ziegler, and Bruno Weisenberger for their help regarding the administration of the tests and Karin Divers-Trapp for language editing and proofreading of the manuscript.

\section{Authors' contributions}

WT developed the BDST and the BDST-Android ${ }^{\circledR}$ app and was conducting the analysis and writing the manuscript. SR, AH, PB, and SD contributed to the development of the objectives, interpretation of results, and manuscript writing. GH contributed to the development of the objectives, interpretation and discussion of results, and manuscript drafting. All authors had the opportunity to review the final manuscript and all approved the decision to submit for publication.

\section{Funding}

The authors received no specific funding for this work.

\section{Availability of data and materials}

The datasets used and/or analyzed during the current study and the APK file to install the BDST app on Android ${ }^{\circledR}$ devices are available from the corresponding author on reasonable request

\section{Ethics approval and consent to participate}

Written informed consent was obtained either from participants themselves or from their legal guardians after a complete description of the study. The study protocol was approved by the Ethical Review Board of the University of Bamberg.

\section{Consent for publication}

Not applicable.

\section{Competing interests}

The authors declare that they have no competing interests.

\section{Author details}

'Department of Psychiatry, Sozialstiftung Bamberg, St-.Getreu-Straße 18, 96049 Bamberg, Germany. ${ }^{2}$ Department of Physiological Psychology, Otto-Friedrich University Bamberg, Markusplatz 3, 96045 Bamberg, Germany. ${ }^{3}$ Department of Geriatric Rehabilitation, Sozialstiftung Bamberg, St-.Getreu-Straße 18, 96049 Bamberg, Germany.
Received: 7 September 2020 Accepted: 22 January 2021

Published online: 05 March 2021

\section{References}

1. Ferri CP, Prince M, Brayne C, Brodaty H, Fratiglioni L, Ganguli M, Hall K, Hasegawa K, Hendrie H, Huang Y, Jorm A, Mathers C, Menezes PR, Rimmer E, Scazufca M, Alzheimer's Disease International. Global prevalence of dementia: a Delphi consensus study. Lancet. 2005;366(9503):2112-7.

2. World Health Organization. 2019. https://www.who.int/en/news-room/factsheets/detail/dementia. Accessed 21 Jul 2020

3. Alzheimer's Disease International. 2018. World Alzheimer Report 2018. https://www.alz.co.uk/research/WorldAlzheimerReport2018.pdf. Accessed 21 Jul 2020.

4. Sternberg SA, Wolfson C, Baumgarten M. Undetected dementia in community-dwelling older people: the Canadian Study of Health and Aging. J Am Geriatr Soc. 2000;48:1430-4.

5. Briggs R, Dyer A, Nabeel S, Collins R, Doherty J, Coughlan T, O'Neill D, Kennelly SP. Dementia in the acute hospital: the prevalence and clinical outcomes of acutely unwell patients with dementia. QJM. 2017;110(1):33-7.

6. Sommerlad A, Perera G, Singh-Manoux A, Lewis G, Stewart R, Livingston G. Accuracy of general hospital dementia diagnoses in England: sensitivity, specificity, and predictors of diagnostic accuracy 2008-2016. Alzheimers Dement. 2018;14(7):933-43.

7. Brooker D, Fontaine JL, Evans S, Bray J, Saad K. Public health guidance to facilitate timely diagnosis of dementia: Alzheimer's Cooperative Valuation in Europe recommendations. Int J Geriatr Psychiatry. 2014:29(7):682-93.

8. Department of Health and Social Care UK. Living well with dementia: a national dementia strategy: Department of Health; 2009. https://www.gov. uk/government/publications/living-well-with-dementia-a-national-dementiastrategy. Accessed 21 Jul 2020

9. Prince M, Bryce R, Ferri C. World Alzheimer Report 2011: the benefits of early diagnosis and intervention. Alzheimers Dis Int. 2011; https://www.alz. co.uk/research/WorldAlzheimerReport2011.pdf. Accessed 21 Jul 2020

10. Pimouguet C, Lavaud T, Dartigues J, Helmer C. Dementia case management effectiveness on health care costs and resource utilization: a systematic review of randomized controlled trials. J Nutr Health Aging. 2010;14(8):669-76.

11. Banerjee S, Wittenberg R. Clinical and cost effectiveness of services for early diagnosis and intervention in dementia. Int J Geriatr Psychiatry. 2009;24(7): $748-54$

12. Getsios D, Blume S, Ishak KJ, Maclaine G, Hernández L. An economic evaluation of early assessment for Alzheimer's disease in the United Kingdom. Alzheimers Dement. 2012;8(1):22-30.

13. Moyer VA. Screening for cognitive impairment in older adults: US Preventive Services Task Force recommendation statement. Ann Intern Med. 2014; 160(11):791-7.

14. Bickel H, Hendlmeier I, Heßler JB, Junge MN, Leonhardt-Achilles S, Weber J, Schäufele $M$. The prevalence of dementia and cognitive impairment in hospitals. Dtsch Arztebl Int. 2018;115(44):733-40.

15. Hendlmeier I, Bickel H, Heßler-Kaufmann JB, Schäufele M. Care challenges in older general hospital patients : impact of cognitive impairment and other patient-related factors. Z Gerontol Geriatr. 2019;52(Suppl 4):212-21.

16. Watkin L, Blanchard MR, Tookman A, Sampson EL. Prospective cohort study of adverse events in older people admitted to the acute general hospital: risk factors and the impact of dementia. Int J Geriatr Psychiatry. 2012;27:76-82

17. Bail K, Berry H, Grealish L, Draper B, Karmel R, Gibson D, Peut A Potentially preventable complications of urinary tract infections, pressure areas, pneumonia, and delirium in hospitalised dementia patients: retrospective cohort study. BMJ Open. 2013; https://doi.org/1 0.1136/bmjopen-2013-002770

18. Aminzadeh F, Dalziel WBB. Older adults in the emergency department: a systematic review of patterns of use, adverse outcomes, and effectiveness of interventions. Ann Emerg Med. 2002:39:238-47.

19. Deutsche Gesellschaft für Psychiatrie und Psychotherapie, Psychosomatik und Nervenheilkunde (DGPPN), Deutsche Gesellschaft für Neurologie (DGN). S3-Leitlinie Demenzen. 2016. https://www.awmf.org/uploads/tx_szleitlinien/ 038-013| S3-Demenzen-2016-07.pdf. Accessed 21 Jul 2020.

20. NICE National institute for health and care excellence. Dementia: assessment, management and support for people living with dementia and their carers (NG 97). 2018. https://www.nice.org.uk/guidance/ng97/chapter/ 
Recommendations\#interventions-to-promote-cognition-independence-andwellbeing. Main page archived at: https://www.webcitation.org/5FH82xq6d. Accessed 21 Jul 2020.

21. Rabins PV, Rovner BW, Rummans T, Schneider LS, Tariot PN. Guideline Watch (October 2014): practice guideline for the treatment of patients with alzheimer's disease and other dementias. Am Psychiatr Assoc. 2014, 2014; https://psychiatryonline.org/pb/assets/raw/sitewide/practice_guidelines/ guidelines/alzheimerwatch.pdf. Accessed 21 Jul 2020

22. Trapp W, Weisenberger B, Düclos D, Lautenbacher S, Mitznegg M, Meyrer R, Hajak G. The Bamberg Dementia Screening Test (BDST) - first evidence regarding the diagnostic usability of a "true bedside" test for geriatric inpatients. Z Neuropsychol. 2015;26:161-70.

23. McKhann GM, Knopman DS, Chertkow H, Hyman BT, Jack CR Jr, Kawas CH, Klunk WE, Koroshetz WJ, Manly JJ, Mayeux R, Mohs RC, Morris JC, Rossor MN, Scheltens P, Carrillo MC, Thies B, Weintraub S, Phelps CH. The diagnosis of dementia due to Alzheimer's disease: recommendations from the National Institute on Aging-Alzheimer's Association workgroups on diagnostic guidelines for Alzheimer's disease. Alzheimers Dement. 2011;7:263-9.

24. Rascovsky K, Hodges JR, Knopman D, Mendez MF, Kramer JH, Neuhaus J, van Swieten JC, Seelaar H, Dopper EG, Onyike CU, Hillis AE, Josephs KA, Boeve BF, Kertesz A, Seeley WW, Rankin KP, Johnson JK, GornoTempini ML, Rosen $\mathrm{H}$, Prioleau-Latham CE, Lee A, Kipps CM, Lillo P, Piguet O, Rohrer JD, Rossor MN, Warren JD, Fox NC, Galasko D, Salmon DP, Black SE, Mesulam M, Weintraub S, Dickerson BC, Diehl-Schmid J, Pasquier F, Deramecourt V, Lebert F, Pijnenburg Y, Chow TW, Manes F, Grafman J, Cappa SF, Freedman M, Grossman M, Miller BL. Sensitivity of revised diagnostic criteria for the behavioural variant of frontotemporal dementia. Brain. 2011;134(Pt 9):2456-77.

25. Gorno-Tempini ML, Hillis AE, Weintraub S, Kertesz A, Mendez M, Cappa SF, Ogar JM, Rohrer JD, Black S, Boeve BF, Manes F, Dronkers NF, Vandenberghe R, Rascovsky K, Patterson K, Miller BL, Knopman DS, Hodges JR, Mesulam MM, Grossman M. Classification of primary progressive aphasia and its variants. Neurology. 2011;76(11):1006-14.

26. Goetz CG, Emre M, Dubois B. Parkinson's disease dementia: definitions, guidelines, and research perspectives in diagnosis. Ann Neurol. 2008; 64(Suppl 2):S81-92.

27. McKeith IG, Dickson DW, Lowe J, Emre M, O'Brien JT, Feldman H, Cummings J, Duda JE, Lippa C, Perry EK, Aarsland D, Arai H, Ballard CG, Boeve B, Burn DJ, Costa D, Del Ser T, Dubois B, Galasko D, Gauthier S, Goetz CG, GomezTortosa E, Halliday G, Hansen LA, Hardy J, Iwatsubo T, Kalaria RN, Kaufer D, Kenny RA, Korczyn A, Kosaka K, Lee VM, Lees A, Litvan I, Londos E, Lopez OL, Minoshima S, Mizuno Y, Molina JA, Mukaetova-Ladinska EB, Pasquier F, Perry RH, Schulz JB, Trojanowski JQ, Yamada M, Consortium on DLB. Diagnosis and management of dementia with Lewy bodies: third report of the DLB Consortium. Neurology. 2005;65(12):1863-72.

28. Román GC, Tatemichi TK, Erkinjuntti T, Cummings JL, Masdeu JC, Garcia JH, Amaducci L, Orgogozo JM, Brun A, Hofman A, et al. Vascular dementia: diagnostic criteria for research studies. Report of the NINDS-AIREN international workshop. Neurology. 1993;43(2):250-60.

29. Dubois B, Feldman HH, Jacova C, Hampel H, Molinuevo JL, Blennow K, DeKosky ST, Gauthier S, Selkoe D, Bateman R, Cappa S, Crutch S, Engelborghs S, Frisoni GB, Fox NC, Galasko D, Habert MO, Jicha GA, Nordberg A, Pasquier F, Rabinovici G, Robert P, Rowe C, Salloway S, Sarazin M, Epelbaum S, de Souza LC, Vellas B, Visser PJ, Schneider L, Stern Y, Scheltens $P$, Cummings JL. Advancing research diagnostic criteria for Alzheimer's disease: the IWG-2criteria. Lancet Neurol. 2014;13(6):614-29.

30. Aebi C. Validierung der Neuropsychologischen Testbatterie CERAD-NP: Eine Multi-Center Studie. PhD thesis. Basel: University of Basel; 2002.

31. Folstein MF, Folstein SE, McHugh PR. "Mini-mental state". A practical method for grading the cognitive state of patients for the clinician. J Psychiatr Res. 1975;12(3):189.

32. Yesavage JA, Sheikh Jl. $9 /$ Geriatric Depression Scale (GDS): recent evidence and development of a shorter version. Clin Gerontol. 1986;5:165-73.

33. Schmidt C, Becker H, Zerr I. Cerebrospinal fluid apolipoprotein E concentration and severity of cognitive impairment in patients with newly diagnosed Alzheimer's disease. Am J Alzheimers Dis Other Dement. 2014;29:54-60.

34. Robin X, Turck N, Hainard A, Tiberti N, Lisacek F, Sanchez JC, Müller M. pROC: an open-source package for $\mathrm{R}$ and $\mathrm{S}+$ to analyze and compare ROC curves. BMC Bioinformatics. 2011;12:77.
35. R Core Team. R: A language and environment for statistical computing. Vienna: R Foundation for Statistical Computing; 2020. https://www.Rproject.org/

36. DeLong ER, DeLong DM, Clarke-Pearson DL. Comparing the areas under two or more correlated receiver operating characteristic curves: a nonparametric approach. Biometrics. 1988;44:837-45.

37. Milian M, Leiherr AM, Straten G, Müller S, Leyhe T, Eschweiler GW. The MiniCog versus the Mini-Mental State Examination and the Clock Drawing Test in daily clinical practice: screening value in a German Memory Clinic. Int Psychogeriatr. 2012;24(5):766-74.

38. Nasreddine ZS, Phillips NA, Bédirian V, Charbonneau S, Whitehead V, Collin I, Cummings JL, Chertkow H. The Montreal Cognitive Assessment, MoCA: a brief screening tool for mild cognitive impairment. J Am Geriatr Soc. 2005; 53:695-9.

39. Hsieh S, Schubert S, Hoon C, Mioshi E, Hodges JR. Validation of the Addenbroke's Clinical Examination-III in frontotemporal dementia and Alzheimer's disease. Dement Geriatr Cogn Disord. 2013;36:242-50.

40. Brown J, Pengas G, Dawson K, Brown LA, Clatworthy P. Self administered cognitive screening test (TYM) for detection of Alzheimer's disease: cross sectional study. BMJ. 2009;338:b2030.

41. van de Zande E, van de Nes JC, Jansen I, van den Berg MN, Zwart AF, Bimmel D, Rijkers GT, Andringa G. The Test Your Memory (TYM) test outperforms the MMSE in the detection of $\mathrm{MCl}$ and dementia. Curr Alzheimer Res. 2017;14:598-607.

42. Mathews SB, Arnold SE, Epperson CN. Hospitalization and cognitive decline: can the nature of the relationship be deciphered? Am J Geriatr Psychiatry. 2014;22(5):465-80.

43. Chambers LW, Sivananthan S, Brayne C. Is dementia screening of apparently healthy individuals justified? Adv Prev Med. 2017;2017:9708413. https://doi. org/10.1155/2017/9708413.

44. Shenkin SD, Fox C, Godfrey M, Siddiqi N, Goodacre S, Young J, Anand A, Gray A, Hanley J, MacRaild A, Steven J, Black PL, Tieges Z, Boyd J, Stephen J, Weir CJ, MacLullich AMJ. Delirium detection in older acute medical inpatients: a multicentre prospective comparative diagnostic test accuracy study of the 4AT and the Confusion Assessment Method. BMC Med. 2019; 17(1):138.

45. Knopman DS, Petersen RC, Rocca WA, Larson EB, Ganguli M. Passive casefinding for Alzheimer's disease and dementia in two U.S. communities. Alzheimers Dement. 2011;7:53-60.

46. Solomon A, Ngandu T, Soininen H, Hallikainen MM, Kivipelto M, Laatikainen T. Validity of dementia and Alzheimer's disease diagnoses in Finnish national registers. Alzheimers Dement. 2014;10:303-9.

47. Rizzuto D, Feldman AL, Karlsson IK, Dahl Aslan AK, Gatz M, Pedersen NL. Detection of dementia cases in two Swedish health registers: a validation study. J Alzheimers Dis. 2018;61(4):1301-10.

48. Wilkinson T, Ly A, Schnier C, Rannikmäe K, Bush K, Brayne C, Quinn TJ, Sudlow CLM, UK Biobank Neurodegenerative Outcomes Group and Dementias Platform UK. Identifying dementia cases with routinely collected health data: A systematic review. Alzheimers Dement. 2018;14:1038-51.

49. Fogg C, Meredith P, Bridges J, Gould GP, Griffiths P. The relationship between cognitive impairment, mortality and discharge characteristics in a large cohort of older adults with unscheduled admissions to an acute hospital: a retrospective observational study. Age Ageing. 2017;46:794-801.

\section{Publisher's Note}

Springer Nature remains neutral with regard to jurisdictional claims in published maps and institutional affiliations.

\section{Ready to submit your research? Choose BMC and benefit from:}

- fast, convenient online submission

- thorough peer review by experienced researchers in your field

- rapid publication on acceptance

- support for research data, including large and complex data types

- gold Open Access which fosters wider collaboration and increased citations

- maximum visibility for your research: over $100 \mathrm{M}$ website views per year

At BMC, research is always in progress.

Learn more biomedcentral.com/submissions 